\title{
Effects of Age and Body Mass Index on the Results of Transtrochanteric Rotational Osteotomy for Femoral Head Osteonecrosis
}

\author{
By Yong-Chan Ha, MD, Hee Joong Kim, MD, Shin-Yoon Kim, MD, Ki-Choul Kim, MD, \\ Young-Kyun Lee, MD, and Kyung-Hoi Koo, MD \\ Investigation performed at the Department of Orthopaedic Surgery, Chung-Ang University College of Medicine, Seoul; \\ the Department of Orthopaedic Surgery, Seoul National University College of Medicine, Seoul; and the Department of Orthopaedic \\ Surgery, Kyungpook National University College of Medicine, Daegu, South Korea
}

Background: Advanced-stage osteonecrosis and a large area of necrotic bone are known risk factors for failure of transtrochanteric rotational osteotomy of the hip in patients with osteonecrosis. The purpose of this study was to determine whether there are other risk factors for failure of this osteotomy.

Methods: One hundred and five patients (113 hips) underwent an anterior transtrochanteric rotational osteotomy for the treatment of femoral head osteonecrosis and were followed for a mean of 51.3 months postoperatively. Radiographic failure was defined as secondary collapse or osteoarthritic change. Multivariate analysis was performed to assess factors associated with secondary collapse and osteophyte formation. The Kaplan-Meier product-limit method was used to estimate survival.

Results: Secondary collapse occurred in twenty-seven hips (24\%), and fourteen hips (12\%) were converted to a total hip arthroplasty. At the time of the most recent follow-up, the hip scores according to the system of Merle d'Aubigné et al. ranged from 6 to 18 points (mean, 15.8 points). Multivariate analysis showed that the stage of the necrosis (III or greater) (hazard ratio $=3.28 ; 95 \%$ confidence interval $=1.49$ to 7.24 ), age of the patient (forty years or older) (hazard ratio $=1.08$; $95 \%$ confidence interval $=1.02$ to 1.14 ), body mass index $\left(\geq 24 \mathrm{~kg} / \mathrm{m}^{2}\right)$ (hazard ratio $=1.19 ; 95 \%$ confidence interval $=$ 1.03 to 1.38), and extent of the necrosis (a combined necrotic angle of $\geq 230^{\circ}$ ) (hazard ratio $=1.08 ; 95 \%$ confidence interval $=1.04$ to 1.11 ) were associated with secondary collapse. Seven of the eighty-six hips without collapse showed progression to osteoarthritis. The survival rate at 110 months was $63.4 \%(95 \%$ confidence interval $=51.1 \%$ to $75.7 \%)$ with total hip arthroplasty or radiographic failure as the end point and $56.0 \%$ (95\% confidence interval $=44.6 \%$ to $67.4 \%$ ) with total hip arthroplasty, radiographic failure, or loss to follow-up as the end point.

Conclusions: Our study showed that age, body mass index, and the stage and extent of the osteonecrosis were determining factors for secondary collapse, unsatisfactory clinical results, and conversion to total hip arthroplasty. These factors should be considered when selecting patients for a transtrochanteric rotational osteotomy.

Level of Evidence: Prognostic Level II. See Instructions to Authors for a complete description of levels of evidence.

$\mathrm{O}$ steonecrosis of the femoral head occurs in young adults, and high rates of failure of total hip arthroplasty due to excessive polyethylene wear, periprosthetic osteolysis, and aseptic loosening have been reported in these young patients ${ }^{1-4}$. Although total hip arthroplasty with the use of contemporary articulations is known to have a lower rate of failure ${ }^{5-7}$, treating young patients with femoral head osteonecrosis remains challenging.
Anterior transtrochanteric rotational osteotomy is one of the surgical procedures used to preserve the hip joint. It moves the necrotic portion of the femoral head from the weight-bearing region to a non-weight-bearing region ${ }^{8}$.

Previous studies have demonstrated variable rates of failure after transtrochanteric rotational osteotomy ${ }^{8-15}$. Although Sugioka et al. and other surgeons reported satisfactory outcomes $^{8-12}$, results from Western countries have not been as

Disclosure: The authors did not receive any outside funding or grants in support of their research for or preparation of this work. Neither they nor a member of their immediate families received payments or other benefits or a commitment or agreement to provide such benefits from a commercial entity. 
The Journal of Bone \& Joint Surgery $\cdot$ JbJs.org Volume 92 -A • Number 2 - February 2010
Effects of Age and Body Mass Index on the Results of TRANSTROCHANTERIC Rotational OSTEOTOMY satisfactor $y^{13-15}$. The preoperative stage of the disease and the size of the necrotic portion of the femoral head are factors known to affect the result of the osteotomy ${ }^{8-10}$. Inappropriate patient selection, inadequate surgical technique, and failure of fixation have been associated with poor outcomes after the osteotomy ${ }^{13,15}$.

From 1993 to 2005, we performed 296 anterior transtrochanteric rotational osteotomies in 277 patients who were younger than fifty-five years of age. Although we used magnetic resonance imaging to aid in patient selection, secondary collapse of the femoral head and secondary osteoarthritis after the osteotomy were observed in some patients. Therefore, the purpose of this study was to determine risk factors associated with secondary collapse and osteoarthritic change in an effort to better define the criteria for selecting patients for the osteotomy.

\section{Materials and Methods}

Patient Selection

Crom January 1999 to December 2004, 119 patients (127

hips) who were diagnosed as having femoral head osteo-
necrosis and met the selection criteria for the anterior transtrochanteric rotational osteotomy were operated on. The diagnosis of osteonecrosis was based on findings on radiographs and magnetic resonance imaging ${ }^{16}$. The selection criteria for the osteotomy were osteonecrosis classified, with the modified Ficat system, as stage IIB (a crescentic subchondral line and segmental flattening of the femoral head) or stage III (a sequestrum, a break in the articular cartilage from one end of the affected area to the other, and a normal or increased joint space $)^{17,18}$; an age younger than fifty-five years; a painful hip; and an adequate area of viable bone (an arc of $>120^{\circ}$ between the central vertical line of the femoral head and the posterior margin of the necrotic portion as seen on a midsagittal magnetic resonance imaging scan) (Fig. 1) ${ }^{12}$.

The design and protocol of this retrospective study were approved by the institutional review board at our hospital, and all patients provided informed consent preoperatively.

\section{Demographic Data}

Of the 119 patients (127 hips), fourteen patients (fourteen hips) were lost before thirty-six months (the minimum duration of follow-up) had elapsed. The last evaluations of these fourteen patients were done at nine to thirty months (mean, twenty-five months) postoperatively. None of the patients lost to follow-up had had a total hip arthroplasty or secondary collapse at the time of the last evaluation.

The remaining 105 patients (113 hips) were followed until the time of conversion to total hip arthroplasty or for thirty-six to 108 months (mean, 51.3 months). There were ninety men (ninety-eight hips) and fifteen women (fifteen hips). The mean patient age at the time of the osteotomy was 34.3 years (range, eighteen to fifty-five years). The mean body mass index was $24.0 \mathrm{~kg} / \mathrm{m}^{2}$ (range, 18.5 to $31.1 \mathrm{~kg} / \mathrm{m}^{2}$ ).

The cause of the osteonecrosis of the femoral head was idiopathic in forty-nine hips (forty-five patients), alcohol-

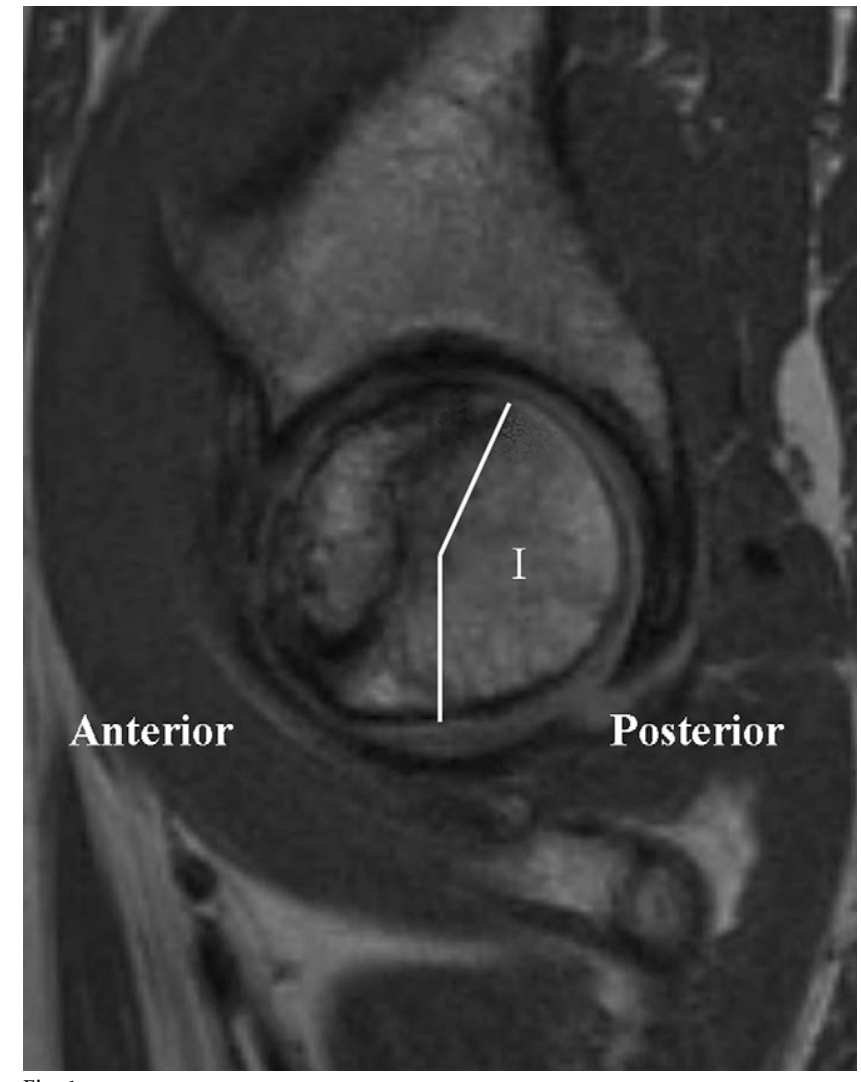

Fig. 1

Midsagittal T1-weighted magnetic resonance imaging scan showing measurement of the angle of the intact area (I), which is defined as the arc between the central vertical line of the femoral head and the posterior margin of the necrotic portion.

associated in forty hips (thirty-seven patients), steroid-induced in nineteen hips (eighteen patients), and posttraumatic in five hips (five patients). Prior to the osteotomy, nineteen patients (twenty-one hips) were sedentary workers, seventy patients (seventy-six hips) performed moderately strenuous labor, nine patients (nine hips) performed labor of intermediate strenuousness, and seven patients (seven hips) performed intensive labor ${ }^{19}$. Preoperatively, according to the modified radiographic classification system of Ficat ${ }^{17,18}$, sixty-nine hips were in stage IIB and forty-four hips were in stage III. The Kerboul combined necrotic angle ${ }^{20,21}$ ranged from $195^{\circ}$ to $260^{\circ}$ (mean, $218.3^{\circ}$ ) (Table I). The preoperative hip scores according to the system of Merle d'Aubigné et al. ${ }^{22}$ ranged from 9 to 16 points (mean, 14.1 points).

\section{Preoperative Measurement of the Arc of the \\ Necrotic Portion on Magnetic Resonance Imaging Scans}

We measured the extent of the osteonecrosis with a modification of the combined necrotic angle of Kerboul et al. ${ }^{20}$ as we described previously ${ }^{21}$. The necrotic angle was measured on magnetic resonance imaging scans instead of radiographs. The midcoronal and midsagittal sections, which showed the largest diameter of the femoral head, were used for the measurement. 
The Journal of Bone \& Joint Surgery $\cdot$ Jbjs.org Volume 92 -A • Number 2 - February 2010
Effects of Age and Body Mass Index on the Results of Transtrochanteric Rotational OSTEOTomy

\section{TABLE I Demographic Data}

No. of patients (hips)
Male:female (no. [\%] of patients)
Age* (yr)
Body mass index* $\left(\mathrm{kg} / \mathrm{m}^{2}\right)$
Cause of osteonecrosis
(no. of patients [no.; \% of hips])
Alcohol-associated
Steroid-induced
Posttraumatic
Idiopathic
Stage (no. [\%] of hips)
IIB
III

Strenuousness of occupation (no. of patients [no.; \% of hips])

\section{Sedentary}

Moderate

Intermediate

Intensive

Combined necrotic angle* (deg)

*The values are given as the mean and standard deviation with the range in parentheses.

The angle of the necrotic portion on the midcoronal image (A) and the angle of the necrotic portion on the midsagittal image (B) were measured, and the combined necrotic angle was calculated as A + B (Fig. 2).
105 (113)

90 (86\%):15 (14\%)

$34.3 \pm 8.6(18-55)$

$24.0 \pm 2.7(18.5-31.1)$

$37(40 ; 35 \%)$

$18(19 ; 17 \%)$

$5(5 ; 5 \%)$

$45(49 ; 43 \%)$

$69(61 \%)$

$44(39 \%)$

$19(21 ; 18 \%)$

$9(9 ; 9 \%)$

$7(7 ; 7 \%)$

$218.3 \pm 12.9(195-260)$
$70(76 ; 67 \%)$

\section{Operative Technique and Postoperative Care}

The anterior transtrochanteric rotational osteotomies were performed by one surgeon (K.-H.K.) using a technique that has been described by Sugioka et al. ${ }^{8,9}$. The osteotomy site was fixed with use of a $120^{\circ}$ compression hip screw (Solco, Seoul, South Korea). Postoperative care consisted of the use of crutches to walk with protected weight-bearing for three to six months, until there was radiographic evidence of osseous union of the osteotomy site.

\section{Follow-up Evaluations}

Follow-up evaluations were performed at three, six, nine, and twelve months postoperatively and every six months thereafter. Patients who had not returned for regularly scheduled visits were contacted by telephone.

Clinical assessment was done according to the system of Merle d'Aubigné et al. ${ }^{22}$, which allots up to 6 points each for pain, mobility, and gait. A score of 17 or 18 points was recorded as an excellent result; 15 or 16 points, as a good result; 13 or 14 points, as a fair result; and $\leq 12$ points, as a poor result.

All of the patients underwent a bone scan at two to four weeks postoperatively to assess the viability of the femoral head.

Radiographic assessment included determination of whether there was postoperative collapse of the newly established weight-bearing area of the femoral head, osteophyte formation around the femoral head, or osteoarthritic change. We considered the six-week radiographs as the baseline studies to be used for comparison. Secondary collapse was defined as subsidence of the articular surface exceeding $2 \mathrm{~mm}$ as compared with the contour on the baseline radiograph ${ }^{12}$. Osteophyte formation was defined as spurs around the femoral head with a thickness exceeding $3 \mathrm{~mm}$ as compared with the contour on the baseline radiograph ${ }^{23}$. We measured the minimum width of the

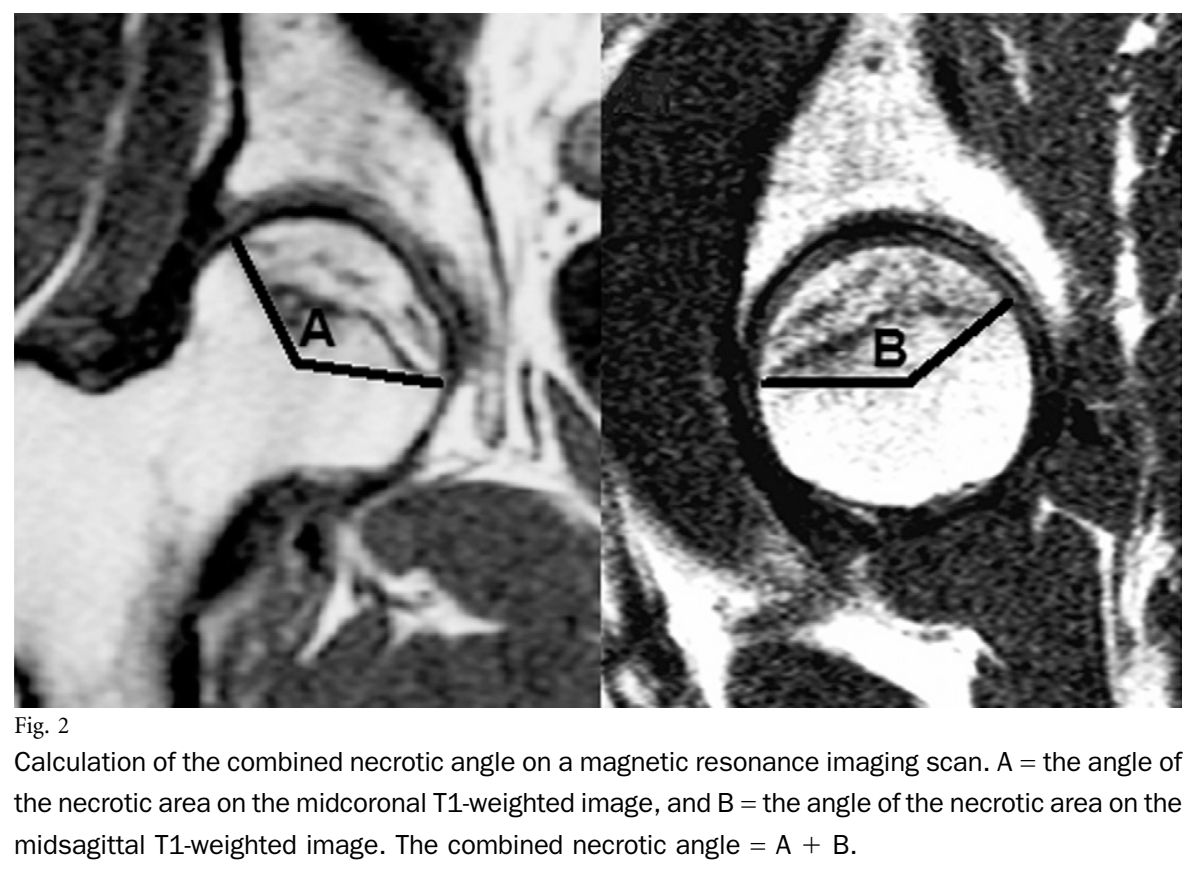


The Journal of Bone \& Joint Surgery - Jbjs. org Volume 92-A • Number $2 \cdot$ February 2010
Effects of Age and Body Mass Index on the Results of Transtrochanteric Rotational Osteotomy hip joint space to determine osteoarthritic change, with a width of $\leq 2.0 \mathrm{~mm}$ considered to be joint space narrowing ${ }^{24}$.

We calculated the time from the index osteotomy to conversion to a total hip arthroplasty for patients who underwent such a conversion during the study period.

\section{Statistical Analysis}

The sex, age, body mass index, and occupation of the patient; the cause and stage of the osteonecrosis; and the combined necrotic angle were assessed to determine the relationships between these variables and secondary collapse, osteophyte formation, hip score, and necessity for conversion to total hip arthroplasty. We used a chi-square test or Fisher exact test for categorical variables and a $t$ test or analysis of variance for numerical variables. All reported $\mathrm{p}$ values were two-sided, and a $\mathrm{p}$ value of $<0.05$ was used to determine significance.

Multivariate analysis was performed. Variables that had a $\mathrm{p}$ value of $<0.10$ (age, body mass index, stage, and combined necrotic angle) were included in the multivariate model. The Cox proportional-hazards frailty model, in which the association between failure times is explicitly modeled with a randomeffect term (commonly called the "frailty"), was carried out to identify independent factors with regard to secondary collapse and osteophyte formation ${ }^{25,26}$. We also performed a sensitivity analysis with a Cox proportional hazards model using just one randomly chosen hip for the eight patients who had undergone bilateral osteotomy, to eliminate the issue of clustering. In addition, we tried to assess age, body mass index, stage, and combined necrotic angle retrospectively in an attempt to find cutoff values.

The Kaplan-Meier product-limit method was performed to estimate survival ${ }^{27}$. We performed three analyses: a best-case scenario with total hip arthroplasty as the end point; a middlecase scenario with total hip arthroplasty or radiographic failure (secondary collapse of the femoral head or osteoarthritic change) as the end point; and a worst-case scenario with total hip arthroplasty, radiographic failure, or loss to follow-up as the end point.

\section{Source of Funding}

There was no external funding for this study.

\section{Results}

\section{Postoperative Scintigraphy}

$A$ ll hips showed adequate perfusion of the proximal seg$A$ ment, indicating preservation of the medial femoral circumflex artery. Uptake of radionuclide was increased at the site of the osteotomy.

\section{Secondary Collapse and Conversion to Total Hip Arthroplasty}

Secondary collapse of the newly established weight-bearing area of the femoral head developed in twenty-seven hips (24\%). The mean amount of time from the osteotomy to the secondary collapse was 20.6 months (range, three to thirty-six months). Twenty of the twenty-seven hips with secondary collapse had osteoarthritic changes, and fourteen of the twenty osteoarthritic hips were converted to a total hip arthroplasty. The mean period of time from the onset of the secondary collapse to the total hip arthroplasty was 9.1 months (range, three to seventeen months).

There were no significant differences between the group with collapse and the group without collapse with regard to the sex $(p=0.189)$ or occupation $(p=0.827)$ of the patient or the cause of the osteonecrosis $(\mathrm{p}=0.586)$. However, there were significant differences between the two groups with regard to the stage of the osteonecrosis $(\mathrm{p}=0.023)$, age $(\mathrm{p}<0.001)$, body mass index $(\mathrm{p}<0.001)$, and combined necrotic angle $(\mathrm{p}<$ $0.001)$.

There were no significant differences between the group that had conversion to a total hip arthroplasty and the group that did not with regard to the sex $(\mathrm{p}=0.470)$ or occupation $(\mathrm{p}=0.094)$ of the patient or the cause of the osteonecrosis $(\mathrm{p}=$ $0.584)$. However, there were significant differences between the two groups with regard to age $(\mathrm{p}<0.001)$, the stage of the osteonecrosis $(\mathrm{p}=0.038)$, the body mass index $(\mathrm{p}<0.001)$, and the combined necrotic angle $(\mathrm{p}<0.001)$.

Multivariate analysis with use of the Cox proportionalhazards frailty model showed that the stage of the osteonecrosis (hazard ratio $=3.28 ; 95 \%$ confidence interval $=1.49$ to 7.24 ), age (hazard ratio $=1.08 ; 95 \%$ confidence interval $=1.02$ to 1.14 ), body mass index (hazard ratio $=1.19 ; 95 \%$ confidence interval $=1.03$ to 1.38 ), and extent of the necrotic area (hazard ratio $=1.08 ; 95 \%$ confidence interval $=1.04$ to 1.11 ) were factors determining secondary collapse.

In the sensitivity analysis of one hip of each patient, the hips of patients with an age of forty years or older (hazard ratio $=$ 2.77; $95 \%$ confidence interval $=1.08$ to 7.16 ), a body mass index of $\geq 24 \mathrm{~kg} / \mathrm{m}^{2}$ (hazard ratio $=3.20 ; 95 \%$ confidence interval $=1.03$ to 8.87 ), an osteonecrosis stage of III or greater (hazard ratio $=2.66 ; 95 \%$ confidence interval $=1.22$ to 5.79 ), and a combined necrotic angle of $\geq 230^{\circ}$ (hazard ratio $=7.78$; $95 \%$ confidence interval $=2.86$ to 17.78 ) were associated with an increased risk of secondary collapse.

\section{Osteophyte Formation and Osteoarthritic Change in the Group without Collapse}

Secondary collapse of the femoral head did not occur in eightysix hips (76\%), and none of them had undergone a total hip arthroplasty as of the time of the latest follow-up.

At the final evaluation, osteophyte formation (range, 3 to $12 \mathrm{~mm}$; mean, $5.3 \mathrm{~mm}$ ) was observed in thirty-seven $(43 \%)$ of the eighty-six hips without secondary collapse. The mean period from the osteotomy to the osteophyte formation was 20.6 months (range, three to thirty-six months). Of these thirtyseven hips, seven showed radiographic evidence of joint space narrowing, which became definite thirty-six to sixty-three months (mean, 46.1 months) postoperatively.

There were no significant differences between the group with osteophyte formation and the group without osteophyte formation with regard to the sex $(\mathrm{p}=0.726)$, age $(\mathrm{p}=0.795)$, occupation $(\mathrm{p}=0.664)$, or body mass index $(\mathrm{p}=0.894)$ of the 
The Journal of Bone \& Joint SURgery $\cdot$ JBJS. org Volume 92 -A • Number 2 - February 2010
Effects of Age and Body Mass Index on the Results of

Transtrochanteric Rotational OSTEOTomy

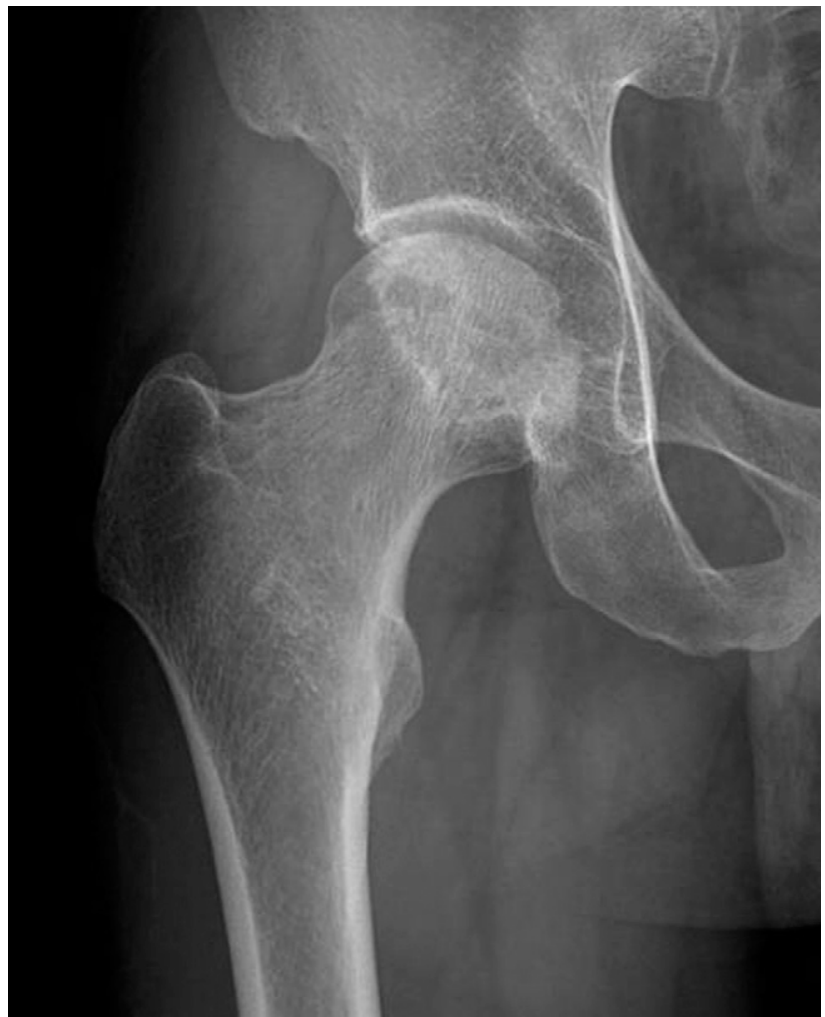

Fig. 3-A

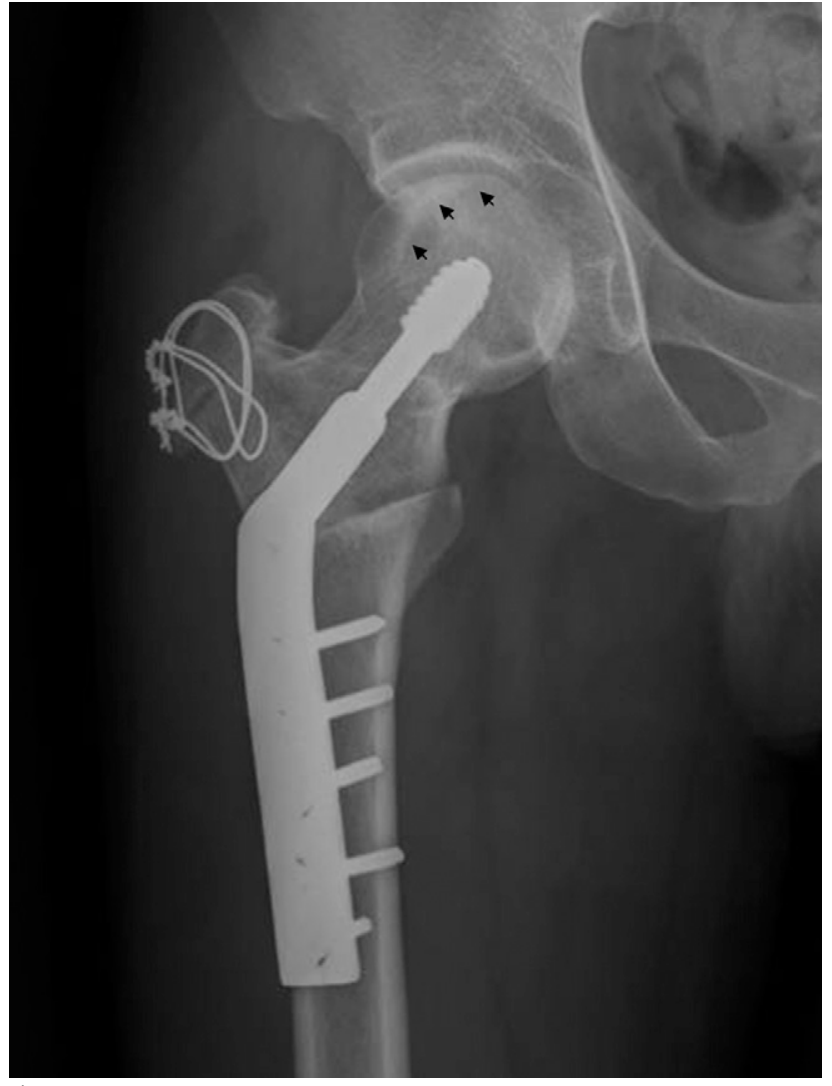

Fig. 3-B

Figs. 3-A, 3-B, and 3-C A forty-five-year-old man with osteonecrosis of the right femoral head and a body mass index of $28.8 \mathrm{~kg} / \mathrm{m}^{2}$. Fig. 3-A

Preoperative anteroposterior radiograph of the hip. Fig. 3-B Anteroposterior radiograph of the hip made six weeks postoperatively. The newly established viable bone in the weight-bearing area below the dome of the acetabulum is thin and beak-shaped (arrows).

patient; the combined necrotic angle $(\mathrm{p}=0.663)$; or the cause of the osteonecrosis $(\mathrm{p}=0.631)$. However, the prevalence of osteophyte formation was higher in stage-III hips $(\mathrm{p}<0.001)$. Cox regression analysis showed that an osteonecrosis stage of III or more was an independent predictor of osteophyte formation (hazard ratio $=4.00 ; 95 \%$ confidence interval $=2.05$ to 7.82) $(\mathrm{p}<0.001)$.

\section{Clinical Results}

A delayed deep infection developed in one hip at thirteen months after the osteotomy. It was successfully treated with removal of the compression hip screw, débridement, and administration of antibiotics. Delayed union of the osteotomy site with excessive varus occurred in one hip. Nonunion of the greater trochanter osteotomy site occurred in four hips. All of these hips were asymptomatic and had no additional intervention.

Seventeen hips had limitations of abduction and external rotation, making it difficult for the patients to put on their shoes and socks. The operatively treated limb was shortened by $>1 \mathrm{~cm}$ (range, 1 to $2 \mathrm{~cm}$; mean, $1.4 \mathrm{~cm}$ ) in twenty-seven cases. Thirty-one patients (thirty-one hips) had a limp, which was mild in twenty-six and moderate in five. However, none of these patients used a crutch or cane.
Patients who had osteophyte formation had significantly less flexion $(\mathrm{p}<0.001)$, abduction $(\mathrm{p}=0.040)$, internal rotation $(\mathrm{p}<0.001)$, and external rotation $(\mathrm{p}=0.002)$ than those who did not.

The mean hip score according to the system of Merle d'Aubigné et al. was 15.8 points (range, 6 to 18 points) at the most recent follow-up visit or the last follow-up evaluation before conversion to a total hip arthroplasty. Fifty-seven hips (50\%) had an excellent score; thirty-eight (34\%), a good score; four $(4 \%)$, a fair score; and fourteen (12\%), a poor score.

The mean hip score was 16.8 points (range, 8 to 18 points) in the group without collapse and 12.6 points (range, 6 to 18 points) in the group that had collapse $(\mathrm{p}<0.001)$. The mean hip score was 16.5 points (range, 15 to 18 points) in the group with osteophyte formation and 17.2 points (range, 15 to 18 points) in the group without osteophyte formation $(\mathrm{p}=0.132)$.

The hip scores were not significantly affected by the sex $(\mathrm{p}=0.830)$ or occupation $(\mathrm{p}=0.135)$ of the patient or by the cause $(\mathrm{p}=0.307)$ or stage of the osteonecrosis $(\mathrm{p}=0.053)$; however, they were significantly influenced by age $(p=0.012)$, body mass index $(\mathrm{p}<0.001)$, and the combined necrotic angle $(\mathrm{p}<0.001)$. A higher likelihood of an unsatisfactory result was associated with an age of forty years or older (odds ratio $=8.26$; $95 \%$ confidence interval $=1.99$ to 34.33 ), a body mass index of 
The Journal of Bone \& Joint Surgery · Jbjs.org Volume 92-A • Number 2 - February 2010

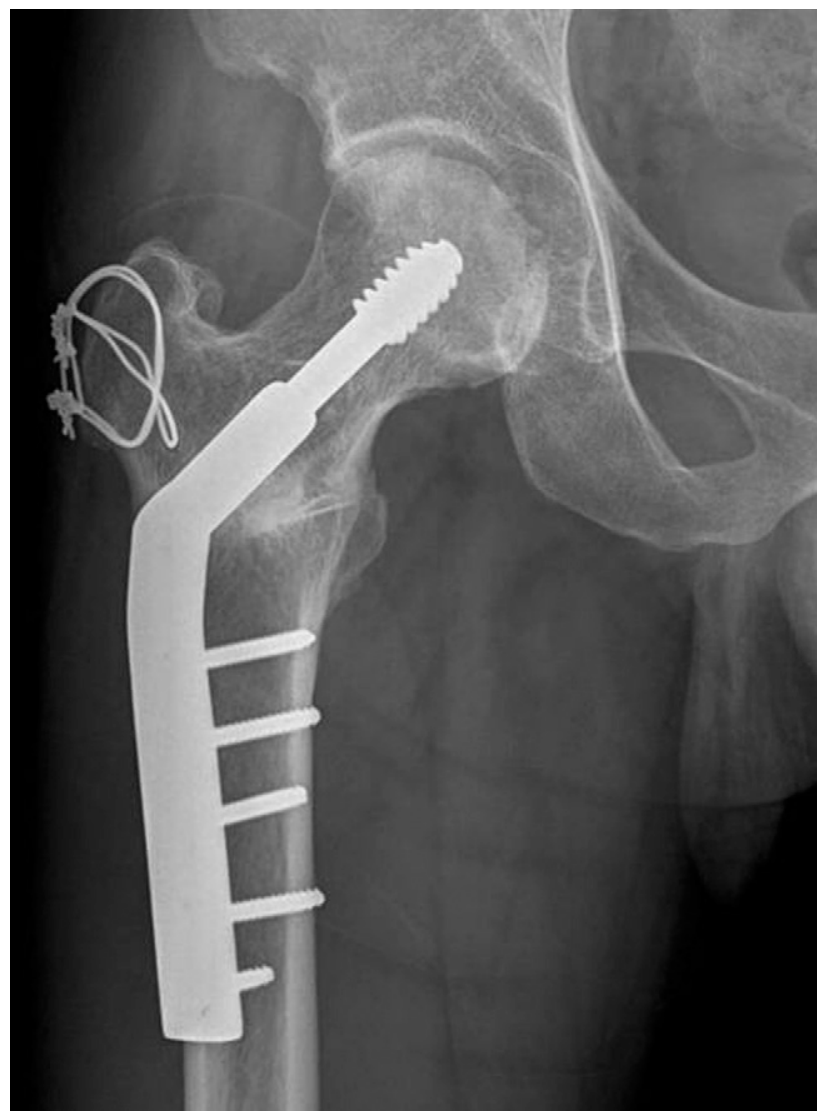

Fig. 3-C

Follow-up radiograph, made at twenty-four months after the operation, showing secondary collapse of the newly established weight-bearing area of the femoral head.

$\geq 24 \mathrm{~kg} / \mathrm{m}^{2}$ (odds ratio $=5.79 ; 95 \%$ confidence interval $=1.07$ to 31.36 ), and a combined necrotic angle of $\geq 230^{\circ}$ (odds ratio $=$ 9.97; $95 \%$ confidence interval $=2.55$ to 38.91 ).

\section{Survival Analysis}

The survival rate at 110 months was $87.2 \%$ (95\% confidence interval $=79.3 \%$ to $92.2 \%$ ) with total hip arthroplasty as the end point (best-case scenario), 63.4\% (95\% confidence interval = $51.1 \%$ to $75.7 \%$ ) with total hip arthroplasty or radiographic failure as the end point (middle-case scenario), and 56.0\% (95\% confidence interval $=44.6 \%$ to $67.4 \%$ ) with total hip arthroplasty, radiographic failure, or loss to follow-up as the end point (worst-case scenario) (Fig. 4).

\section{Discussion}

Transtrochanteric rotational osteotomy is theoretically an ideal method for preserving a hip joint affected by osteonecrosis $^{8,9}$. The necrotic portion can be removed from the weight-bearing zone and replaced with intact cartilage and bone with use of this osteotomy. However, the reported results of the osteotomy have been inconsistent ${ }^{8-15}$. Studies from Japan and Korea have demonstrated satisfactory results ${ }^{8-12}$, but such favorable results have not been reproduced by surgeons in
Effects of Age and Body Mass Index on the Results of

Transtrochanteric Rotational OSTEOTOMY
Western countries ${ }^{13-15}$. The striking difference in the results has been thought to be related to differences in the preoperative stage of the necrosis, the extent of the necrosis, the surgical technique, the method of fixation, and/or the postoperative management. Secondary collapse after the osteotomy has been the main cause of failure.

To date, there is little information regarding the association of patient age or body mass index with the result of anterior transtrochanteric rotational osteotomy. Our study showed that body mass index and age as well as the extent and stage of the osteonecrosis are important factors determining secondary collapse after this osteotomy.

In our study, thirteen patients with secondary collapse and thirty-seven patients with osteophyte formation did not require a hip replacement during the study period although they experienced intermittent pain and limping. Dean and Cabanela ${ }^{13}$ reported that, of eighteen hips treated with the osteotomy, fifteen showed further collapse of the femoral head and only three had a satisfactory result. They suggested there might be race-dependent differences in body weight, body mass index, and/or the anatomy of the hip capsule between Korean or Japanese patients and white patients that might have influenced the outcome of the osteotomy and the need for hip replacement. Although collapse and osteophyte formation frequently lead to a poor clinical result and the subsequent need for a total hip arthroplasty, the indications for total hip arthroplasty vary considerably among institutions, among geographical areas, and among cultures. In some cultures, patients with a notable degree of clinical and radiographic progression of osteoarthritis are much less likely to be treated with total hip replacement because of differences in tolerance to pain and disability as well as socioeconomic factors. Thus, we analyzed three scenarios, with the middle-case scenario (a survival rate of $63.4 \%$ with a total hip arthroplasty, secondary collapse of the femoral head, or osteoarthritic change as the end point) perhaps being the best indication of the overall results of this procedure.

We could not explain why secondary collapse was more frequent in patients who were forty years of age or older with a body mass index of $\geq 24 \mathrm{~kg} / \mathrm{m}^{2}$. Secondary collapse may represent a stress fracture of the newly established intact portion of the femoral head in the weight-bearing region (Figs. 3-A, 3-B, and $3-C)^{10}$. This intact portion was usually thin and beak-shaped. In both men and women, age-related osteopenia begins near the age of forty years and progresses linearly at a rate of $0.5 \%$ to $1 \%$ per year, accounting for nearly $40 \%$ of the total bone loss accrued by the age of seventy years ${ }^{28}$. Such bone loss results in increased porosity, decreased mineralization, and ultimately increased fracture risk $^{28}$. In overweight patients, an excessive load can be induced on the femoral head, which leads to a stress fracture and secondary collapse of the newly formed weightbearing portion.

In our study, thirty-seven (43\%) of eighty-six hips without collapse had osteophyte formation around the femoral head during the study period. This led to secondary osteoarthritis with a narrow joint space in seven (19\%). Osteophyte 


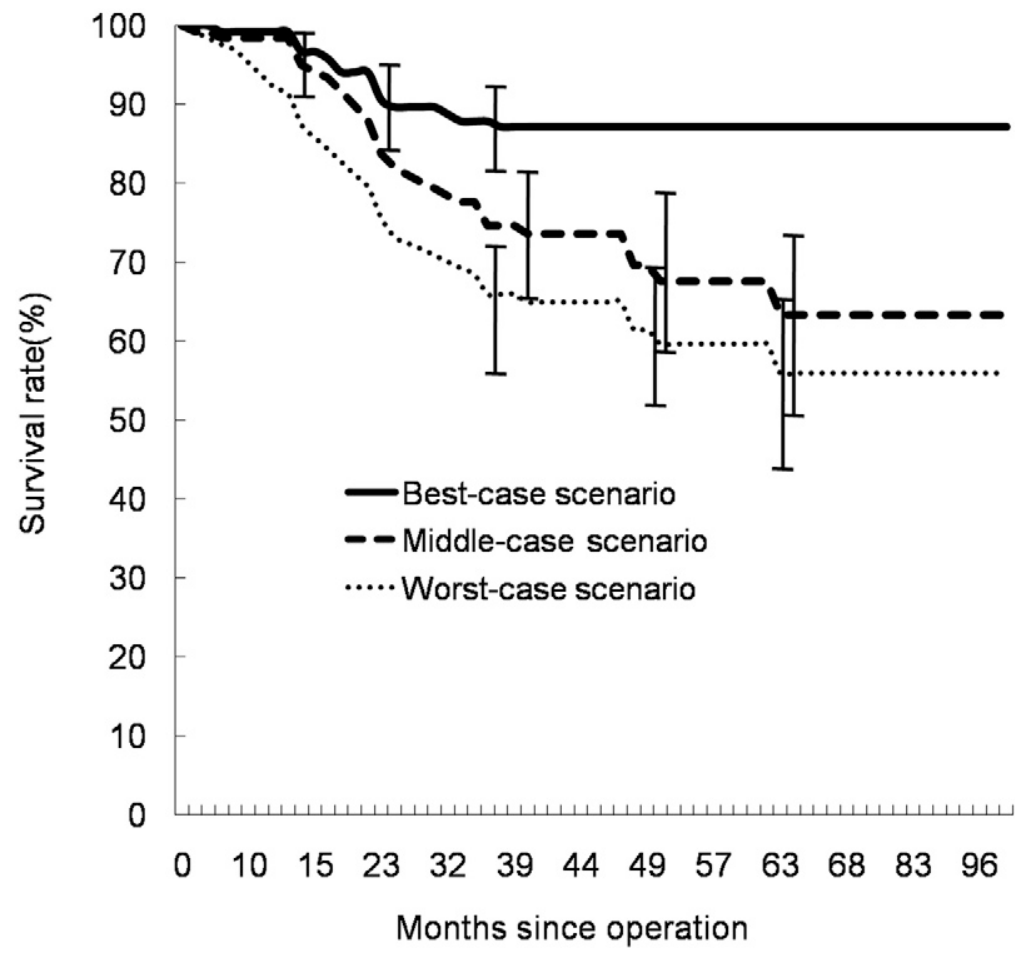

Fig. 4

Kaplan-Meier survival curves with 95\% confidence intervals showing the best-case scenario (conversion to total hip arthroplasty), the middle-case scenario (conversion to total hip arthroplasty or radiographic failure), and the worst-case scenario (conversion to total hip arthroplasty, radiographic failure, or loss to follow-up) after anterior transtrochanteric rotational osteotomy.

formation has been known to cause impingement of the hip joint and subsequent osteoarthritis ${ }^{10,29}$. Sugano et al. reported postoperative osteophyte formation around the femoral head in $39 \%$ of the stage-III hips in their study at a mean of 6.3 years postoperatively ${ }^{10}$. Hisatome et al. observed the same phenomenon in $64 \%$ of their cases during a mean follow-up period of 6.4 years $^{29}$.

Limitations of our study include a relatively short followup period, the risk of selection bias, and possible effects of unmeasured confounders. Previous studies have shown that most of the collapse of the new weight-bearing area develops within three years postoperatively ${ }^{8-12}$. Although the three-year follow-up period was sufficient to assess the secondary collapse, it was not sufficient to evaluate the effect of osteophyte formation on the outcome of the osteotomy. It should be noted that we performed the osteotomy in patients who had marked segmental collapse when they were younger than thirty years of age. We did not evaluate alcohol intake or steroid use after the osteotomy, although these factors might have influenced the results of the osteotomy. The percentage of necrotic volume has been identified as an important factor in the collapse of an osteonecrotic femoral head ${ }^{30-32}$. However, we did not measure the percentage of necrotic volume in our patients. Previous studies have shown that some patients remain asymptomatic without any treatment and also that other joint- preserving procedures can be effective in the treatment of femoral head osteonecrosis ${ }^{21,33}$. Anterior transtrochanteric rotational osteotomy is a technically demanding operation that requires a prolonged period of rehabilitation. Delayed union and malunion of the osteotomy site, nonunion of the greater trochanter, and shortening of the operatively treated limb may be complications following this osteotomy. To verify the effectiveness of the anterior transtrochanteric rotational osteotomy, it should be compared with other procedures in a randomized clinical trial.

The success rate of anterior transtrochanteric rotational osteotomy may be improved by more efficient selection of patients. The procedure should be performed in the early stages of the disease, before marked collapse of the head occurs. The viable portion of the femoral head should be of such a size that restoration of an adequate weight-bearing articular surface is possible ${ }^{8,10}$. The use of magnetic resonance imaging instead of plain radiographs for the selection of patients improves the success rate of the osteotomy $^{12}$.

This study showed that age, body mass index, and the stage and extent of the osteonecrosis are factors determining secondary collapse after anterior transtrochanteric rotational osteotomy and should be considered in the selection of patients for this procedure. 
The Journal of Bone \& Joint Surgery $\cdot$ JbjS. org Volume 92 -A • Number 2 - February 2010
Effects of Age and Body Mass Index on the Results of TRANSTROCHANTERIC Rotational OSTEOTOMY
Yong-Chan Ha, MD

Department of Orthopaedic Surgery,

Chung-Ang University College of Medicine,

224-1 Heukseok-dong,

Dongjak-gu, Seoul 155-756, South Korea

Hee Joong Kim, MD

Ki-Choul Kim, MD

Young-Kyun Lee, MD

Kyung-Hoi Koo, MD
Department of Orthopaedic Surgery, Seoul National

University College of Medicine,

28 Yeongeon-dong, Jongno-gu,

Seoul 110-744, South Korea.

E-mail address for K.-H. Koo: khkoo@snu.ac.kr

Shin-Yoon Kim, MD

Department of Orthopaedic Surgery, Kyungpook National

University College of Medicine, 200 Dongduk-ro,

Jung-gu, Daegu 700-721, South Korea

\section{References}

1. Cornell $\mathrm{CN}$, Salvati EA, Pellicci PM. Long-term follow-up of total hip replacement in patients with osteonecrosis. Orthop Clin North Am. 1985;16:757-69.

2. Saito $S$, Saito $M$, Nishina $T$, Ohzono $K$, Ono K. Long-term results of total hip arthroplasty for osteonecrosis of the femoral head. A comparison with osteoarthritis. Clin Orthop Relat Res. 1989;244:198-207.

3. Katz RL, Bourne RB, Rorabeck $\mathrm{CH}$, McGee $\mathrm{H}$. Total hip arthroplasty in patients with osteonecrosis of the hip. Follow-up observations on cementless and cemented operations. Clin Orthop Relat Res. 1992;281:145-51.

4. Kim $\mathrm{YH}, \mathrm{Oh} \mathrm{JH}$, Oh SH. Cementless total hip arthroplasty in patients with osteonecrosis of the femoral head. Clin Orthop Relat Res. 1995;320:73-84.

5. Daniel J, Pynsent PB, McMinn DJ. Metal-on-metal resurfacing of the hip in patients under the age of 55 years with osteoarthritis. J Bone Joint Surg Br. 2004; 86:177-84.

6. Kearns $\mathrm{SR}$, Jamal B, Rorabeck $\mathrm{CH}$, Bourne RB. Factors affecting survival of uncemented total hip arthroplasty in patients 50 years or younger. Clin Orthop Relat Res. 2006;453:103-9.

7. Yoo JJ, Kim YM, Yoon KS, Koo KH, Kim JW, Nam KW, Kim HJ. Contemporary alumina-on-alumina total hip arthroplasty performed in patients younger than forty years: a 5-year minimum follow-up study. J Biomed Mater Res B Appl Biomater. 2006;78:70-5.

8. Sugioka Y. Transtrochanteric anterior rotational osteotomy of the femoral head in the treatment of osteonecrosis affecting the hip: a new osteotomy operation. Clin Orthop Relat Res. 1978;130:191-201.

9. Sugioka $\mathrm{Y}$, Hotokebuchi T, Tsutsui H. Transtrochanteric anterior rotational osteotomy for idiopathic and steroid-induced necrosis of the femoral head. Indications and long-term results. Clin Orthop Relat Res. 1992;277:111-20.

10. Sugano N, Takaoka K, Ohzono K, Matsui M, Saito M, Saito S. Rotational osteotomy for non-traumatic osteonecrosis of the femoral head. J Bone Joint Surg Br. 1992;74:734-9.

11. Inao $S$, Ando M, Gotoh $E$, Matsuno T. Minimum 10-year results of Sugioka's osteotomy for femoral head osteonecrosis. Clin Orthop Relat Res. 1999;368: 141-8.

12. Koo KH, Song HR, Yang JW, Yang P, Kim JR, Kim YM. Trochanteric rotational osteotomy for osteonecrosis of the femoral head. J Bone Joint Surg Br. 2001;83 83-9.

13. Dean MT, Cabanela ME. Transtrochanteric anterior rotational osteotomy for osteonecrosis of the femoral head. Long-term results. J Bone Joint Surg Br. 1993;75:597-601.

14. Langlais F, Fourastier J. Rotation osteotomies for osteonecrosis of the femoral head. Clin Orthop Relat Res. 1997;343:110-23.

15. Tooke SM, Amstutz HC, Hedley AK. Results of transtrochanteric rotational osteotomy for femoral head osteonecrosis. Clin Orthop Relat Res. 1987;224:150-7.

16. Totty WG, Murphy WA, Ganz WI, Kumar B, Daum WJ, Siegel BA. Magnetic resonance imaging of the normal and ischemic femoral head. AJR Am J Roentgenol. 1984;143:1273-80.

17. Ficat RP. Idiopathic bone necrosis of the femoral head. Early diagnosis and treatment. J Bone Joint Surg Br. 1985;67:3-9.
18. Smith SW, Meyer RA, Connor PM, Smith SE, Hanley EN Jr. Interobserver reliability and intraobserver reproducibility of the modified Ficat classification system of osteonecrosis of the femoral head. J Bone Joint Surg Am. 1996;78: 1702-6.

19. Flugsrud GB, Nordsletten L, Espehaug B, Havelin LI, Meyer HE. Risk factors for total hip replacement due to primary osteoarthritis: a cohort study in 50,034 persons. Arthritis Rheum. 2002;46:675-82.

20. Kerboul M, Thomine J, Postel M, Merle d'Aubigné R. The conservative surgical treatment of idiopathic aseptic necrosis of the femoral head. J Bone Joint Surg Br. 1974;56:291-6.

21. Ha YC, Jung WH, Kim JR, Seong NH, Kim SY, Koo KH. Prediction of collapse in femoral head osteonecrosis: a modified Kerboul method with use of magnetic resonance images. J Bone Joint Surg Am. 2006;88 Suppl. 3:35-40.

22. Merle D'Aubigné R, Postel $M$, Mazabraud $A$, Massias $P$, Gueguen J, France $P$. Idiopathic necrosis of the femoral head in adults. J Bone Joint Surg Br. 1965;47: 612-33.

23. Swezey RL, Bjarnason DM. Inhibition of secondary osteophyte formation in rheumatoid arthritis. Rheumatol Rehabil. 1976;15:10-6.

24. Jacobsen $S$, Sonne-Holm $S$, Søballe $K$, Gebuhr P, Lund B. The relationship of hip joint space to self reported hip pain. A survey of 4.151 subjects of the Copenhagen City Heart Study: the Osteoarthritis Substudy. Osteoarthritis Cartilage. 2004;12:692-7.

25. Hougaard P. Frailty models for survival data. Lifetime Data Anal. 1995;1: 255-73.

26. Hougaard P. Analysis of multivariate survival data. Springer; New York: 2000.

27. Kaplan EL, Meier P. Nonparametric estimation from incomplete observations. J Am Stat Assoc. 1958;53:457-81.

28. Parfitt AM. Age-related structural changes in trabecular and cortical bone: celIular mechanisms and biomechanical consequences. Calcif Tissue Int. 1984;36 Suppl. 1:S123-8.

29. Hisatome $T$, Yasunaga $Y$, Takahashi $K$, Ochi M. Progressive collapse of transposed necrotic area after transtrochanteric rotational osteotomy for osteonecrosis of the femoral head induces osteoarthritic change. Mid-term results of transtrochanteric rotational osteotomy for osteonecrosis of the femoral head. Arch Orthop Trauma Surg. 2004;124:77-81.

30. Holman AJ, Gardner GC, Richardson ML, Simkin PA. Quantitative magnetic resonance imaging predicts clinical outcome of core decompression for osteonecrosis of the femoral head. J Rheumatol. 1995;22:1929-33.

31. Nishii T, Sugano N, Ohzono K, Sakai T, Sato Y, Yoshikawa H. Significance of lesion size and location in the prediction of collapse of osteonecrosis of the femoral head: a new three-dimensional quantification using magnetic resonance imaging. J Orthop Res. 2002;20:130-6.

32. Steinberg ME, Bands RE, Parry S, Hoffman E, Chan T, Hartman KM. Does lesion size affect the outcome in osteonecrosis? Clin Orthop Relat Res. 1999;367:262-71.

33. Nam KW, Kim YL, Yoo JJ, Koo KH, Yoon KS, Kim HJ. Fate of untreated asymptomatic osteonecrosis of the femoral head. J Bone Joint Surg Am. 2008; 90:477-84. 